\title{
Cardiac conduction system- A detailed study in 46 cases of sudden death
}

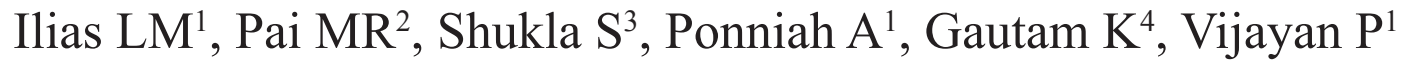 \\ ${ }^{I}$ Department of Pathology, M.E.S Medical College, Perinthalmanna, Kerala, India \\ ${ }^{2}$ Department of Pathology, A.J. Institute of Medical Sciences, Manglore, Karnataka, India \\ ${ }^{3}$ Department of Pathology, Ram Manohar Lohia Institute of Medical Sciences, Lucknow, India \\ ${ }^{4}$ Department of Pathology, Samyak Diagnostic Pvt. Ltd, Lalitpur, Nepal
}

\author{
Keywords: \\ Atherosclerosis; \\ Coronary artery disease; \\ Conduction system \\ abnormalities; \\ Fibromuscular dysplasia; \\ Nodal arteries;
}

\begin{abstract}
Background: Atherosclerotic coronary artery disease is the modern pandemic and is said to be responsible for a major chunk of sudden cardiac deaths. However, in few cases; especially among the young, conduction system abnormalities were found to be the cause of death with absence of significant coronary lesions. These days, examination of the cardiac conduction system during autopsy has been abandoned as it is said to be a time consuming process. The present study was undertaken to highlight the importance of examining the cardiac conduction system in all sudden death cases.
\end{abstract}

Materials and Methods: This study was a prospective one, conducted from June 2007 to June 2009 in the department of Pathology, Kasturba Medical College, Mangalore. Forty six hearts of persons who died suddenly were studied.

Results: Our study showed that even though atherosclerotic coronary lesions were the most common cause of sudden death, cardiac conduction defects also contributed to a significant number of cases; especially in the young. In our study of 46 cases; 6 cases showed only conduction system abnormalities. These were young adults who had died suddenly. The predominant lesion identified in them was fibromuscular dysplasia of the nodal arteries.

Conclusion: A detailed examination of the coronaries and the cardiac conduction system should be made mandatory in all sudden death cases, especially in the young as they will help to throw some light into the cause of death.

\section{INTRODUCTION}

Atherosclerotic coronary artery disease $(\mathrm{CAD})$ is a modern pandemic and is said to be responsible for $>80 \%$ of sudden cardiac deaths (SCD). ${ }^{1}$ In the Indian subcontinent they are responsible for $>25 \%$ of deaths. ${ }^{2}$ However in few cases of SCD, no meaningful coronary lesions were identified.

\section{Correspondence:}

Dr. Laila M. Ilias, $M D$

Department of Pathology

M.E.S Medical College, Perinthalmanna, Kerala, India

E-mail: ilias.laila@gmail.com
As the usual pathophysiologic mechanism responsible for sudden death is ventricular fibrillation, many studies were done on the conduction system (malformation or acquired lesions) to ascertain whether it can be a cause of unexpected sudden death; especially in the young. Different studies showed that conduction system lesions indeed contributed to sudden death; and these lesions were seen in cases with and also without atherosclerotic lesions. Hence it should be pointed out that even though CAD is said to be the major bulk of SCD; conduction system lesions should also be 
looked for even in the presence of severe CAD. ${ }^{1}$

However nowadays, the examination of the cardiac conduction system during autopsy has been ignored as it is said to be a time consuming and essentially an unrewarding experience. ${ }^{3}$

In the present study, we have focused our attention on the conduction system in sudden death cases; to determine whether they have in one way or other contributed to the death of the individual. The aims and objective of the study was to study the morphological and histopathological changes or lesions in the conduction system in cases of sudden death and to study the extent to which these changes contributed to sudden cardiac death

\section{Definition of sudden death}

Sudden death has been defined as natural death occurring instantaneously or within a few hours after onset of symptoms, in a patient who may or may not have known pre-existing disease but in whom the mode and time of death are unexpected. The World Health Organization (WHO) defines sudden death as that occurring within 24 hours of onset of symptoms. ${ }^{4}$ Sudden death includes death from all natural causes but excludes unnatural causes such as homicide, accidents, poisoning or suicide. ${ }^{5}$

\section{MATERIALS AND METHODS}

The present study was a prospective study conducted from June 2007 to June 2009 in the Department of Pathology, Kasturba Medical College, Mangalore. The hearts of persons who died of sudden death with or without a history of heart diseases were studied.

The heart with the proximal part of ascending aorta was removed from the body and fixed in $10 \%$ formalin. The coronary arteries were first studied in situ to note for any thickening or hardening. At $5 \mathrm{~mm}$ intervals, transverse cuts were made along the course of the coronaries and the extent of atherosclerotic changes were noted. Care was taken not to damage the junction of the superior vena cava (SVC) with the right atrial appendage as this site harbored the SA node.

The sinoatrial (SA) node was studied by making an incision extending from the superior venacava (SVC) into the right atrial appendage. Another parallel incision was made lateral to the first one and a rectangular block of tissue was obtained. The nodal artery was looked for grossly and once identified, thin parallel sections were given.

The AV node was examined by making a linear incision just lateral to the coronary sinus ostia, extending up to the medial papillary muscle of the right ventricle. A parallel incision was made $1 \mathrm{~cm}$ lateral to the first one and the block of tissue was removed. This block was divided into two; the lower part containing the muscular part of the interventricular septum (IVS) along with the bundles and the upper part containing the AV node and bundle of His. Thin longitudinal sections were given from the upper part and transverse sections were given from the lower part to study the respective areas.

The hearts were then dissected and studied along the direction of blood flow (Virchow's method). Sections were taken from the coronaries, SA node and atrioventricular (AV) node and stained with haematoxylin and eosin and also with Masson trichrome.

\section{RESULTS}

Forty six hearts were studied of which 44 were males and 2 were females. The youngest and the oldest were a 21 and a 75 year-old male, respectively. The predominant age group involved was above 35 years $(n=41 ; 89.13 \%)$.

Forty six sudden death cases were studied; the predominant cause of sudden death in the present study was atherosclerotic CAD (71.74\%) including the case of hypertrophic cardiomyopathy $(\mathrm{HCM})$ with myocardial

\begin{tabular}{lc}
$\begin{array}{l}\text { Table: } 1 \text { Various lesions found in the heart in } \\
\text { death cases }\end{array}$ \\
\hline \multicolumn{1}{c}{ PATHOLOGICAL LESIONS } & $\begin{array}{c}\text { NO.OF } \\
\text { CASES (\%) }\end{array}$ \\
\hline $\begin{array}{l}\text { Atherosclerotic CAD+Myocardial Infarction (MI) } \\
\text { Hypertrophic cardiomyopathy(HCM) with acute }\end{array}$ & $32(69.57)$ \\
MI & $1(2.17)$ \\
\hline $\begin{array}{l}\text { Valvular heart disease (Mitral stenosis +Pulmonary } \\
\text { stenosis) }\end{array}$ & $2(4.35)$ \\
\hline $\begin{array}{l}\text { Infections (Malarial+Tuberculous myocarditis) } \\
\text { Conduction system abnormalities alone }\end{array}$ & $4(8.7)$ \\
\hline No significant cardiac pathology** & $6(13.04)$ \\
\hline Total & $1(2.17)$ \\
\hline
\end{tabular}

Table 2: Microscopic features in SA node

\begin{tabular}{lc}
\hline \multicolumn{1}{c}{ Microscopic } & Sudden \\
& No. of cases \\
\hline Fibromuscular dysplasia & $5(10.87)$ \\
\hline Fatty infiltration & $9(19.57)$ \\
\hline FMD+ fatty infiltration & $10(21.74)$ \\
\hline FMD+ fatty infiltration+fibrosis & $1(2.17)$ \\
\hline FMD+fibrosis & $1(2.17)$ \\
\hline Myxoid change & $1(2.17)$ \\
\hline Haemorrhage & $1(2.17)$ \\
\hline Unremarkable & $12(26.1)$ \\
\hline Not sampled & $6(13.04)$ \\
\hline Total & $\mathbf{4 6 ( 1 0 0 )}$ \\
\hline
\end{tabular}


Table:3 Distribution by age groups and microscopic features in SA node

\begin{tabular}{|c|c|c|c|c|c|c|c|c|c|c|c|c|c|c|}
\hline \multirow{3}{*}{$\begin{array}{c}\text { Microscopic } \\
\text { features in SA } \\
\text { node }\end{array}$} & \multicolumn{12}{|c|}{ Age Groups } & \multirow{3}{*}{$\begin{array}{l}\text { Total } \\
\text { no of } \\
\text { cases }\end{array}$} & \multirow[b]{3}{*}{$\%$} \\
\hline & \multicolumn{2}{|c|}{$<25$} & \multicolumn{2}{|c|}{$25-34$} & \multicolumn{2}{|c|}{$35-44$} & \multicolumn{2}{|c|}{$45-54$} & \multicolumn{2}{|c|}{$55-64$} & \multicolumn{2}{|c|}{$\geq 65$} & & \\
\hline & $\begin{array}{l}\text { no of } \\
\text { cases }\end{array}$ & $\%$ & $\begin{array}{l}\text { no of } \\
\text { cases }\end{array}$ & $\%$ & $\begin{array}{l}\text { no of } \\
\text { cases }\end{array}$ & $\%$ & $\begin{array}{l}\text { no of } \\
\text { cases }\end{array}$ & $\%$ & $\begin{array}{l}\text { no of } \\
\text { cases }\end{array}$ & $\%$ & $\begin{array}{l}\text { no of } \\
\text { cases }\end{array}$ & $\%$ & & \\
\hline FMD & 0 & 0 & 0 & 0 & 1 & 2.17 & 1 & 2.17 & 2 & 4.35 & 1 & 2.17 & 5 & 10.87 \\
\hline $\begin{array}{l}\text { Fat infiltration } \\
\text { (Fat) }\end{array}$ & 0 & 0 & 0 & 0 & 2 & 4.35 & 2 & 4.35 & 3 & 6.52 & 2 & 4.35 & 9 & 18.75 \\
\hline FMD+Fat & 0 & 0 & 0 & 0 & 1 & 2.17 & 3 & 6.52 & 3 & 6.52 & 3 & 6.52 & 10 & 21.74 \\
\hline FMD+Fat+Fib & 0 & 0 & 0 & 0 & 0 & 0 & 1 & 2.17 & 0 & 0 & 0 & 0 & 1 & 2.17 \\
\hline FMD+ Fib & 0 & 0 & 0 & 0 & 0 & 0 & 0 & 0 & 0 & 0 & 1 & 2.17 & 1 & 2.17 \\
\hline Myxoid change & 0 & 0 & 0 & 0 & 0 & 0 & 0 & 0 & 0 & 0 & 1 & 2.17 & 1 & 2.17 \\
\hline Haemorrhage & 0 & 0 & 0 & 0 & 0 & 0 & 0 & 0 & 0 & 0 & 1 & 2.17 & 1 & 2.17 \\
\hline Unremarkable & 1 & 2.17 & 2 & 4.35 & 5 & 10.87 & 1 & 2.17 & 0 & 0 & 3 & 6.52 & 12 & 26.08 \\
\hline Not sampled & 0 & 0 & 2 & 4.35 & 3 & 6.52 & 1 & 2.17 & 0 & 0 & 0 & 0 & 6 & 13.04 \\
\hline TOTAL & 1 & 2.17 & 4 & 8.7 & 12 & 26.08 & 9 & 19.57 & 8 & 17.4 & 12 & 26.08 & 46 & 100 \\
\hline
\end{tabular}

FMD: Fibromuscular Dysplasia; Fat: Fat infiltration; Fib: Fibrosis

Table 4: Microscopic features of AV node

\begin{tabular}{lcc}
\hline Microscopic features in AV node & $\begin{array}{c}\text { Sudden } \\
\text { No. of cases }\end{array}$ & $\begin{array}{c}\text { Death } \\
(\%)\end{array}$ \\
\hline FMD & $4(8.7)$ \\
\hline Fat & $6(13.04)$ \\
\hline Fib & $7(15.22)$ \\
\hline FMD+Fat & $2(4.35)$ \\
\hline Fat +Fib & $1(2.17)$ \\
\hline FMD+Fib & $3(6.52)$ \\
\hline FMD+Fat+Fib & $3(6.52)$ \\
\hline C.I & $2(4.35)$ \\
\hline Fat+C.I & $2(4.35)$ \\
\hline FMD+Fat+C.I & $1(2.17)$ \\
\hline Fib+C.I & $1(2.17)$ \\
\hline FMD+Fat+Fib+C.I & $2(4.35)$ \\
\hline Fat+Fib+C.I & $2(4.35)$ \\
\hline FMD+Fat+C.I+haemorrhage & $1(2.17)$ \\
\hline FMD+Cal+fat & $1(2.17)$ \\
\hline FMD+Fat+C.I+Cal & $1(2.17)$ \\
\hline Fat+Fib+C.I+Cal & $3(6.52)$ \\
\hline Unremarkable & $1(2.17)$ \\
\hline Not sampled & $3(6.52)$ \\
\hline TOTAL & $\mathbf{4 6}(\mathbf{1 0 0})$ \\
\hline & \\
\hline
\end{tabular}

FMD-Fibromuscular Dysplasia, F.I-Fatty infiltration, Fib-Fibrosis, C.I-chronic inflammation, Cal-calcification

infarction (MI), valvular heart diseases (4.35\%) and infections $(8.7 \%)$ were the other causes. Conduction system abnormalities alone contributed to $13.04 \%$ of cases. (Table 1) With this it becomes very clear that, even though the major cause of sudden death is atherosclerotic coronary heart diseases, conduction system abnormalities is also a major factor $(13.04 \%)$.
Various lesions are seen in SA node (Table 2). Fibromusular dysplasia (FMD) of SA nodal artery was seen in 36.96\% of cases (fig.1A\&1B). The other pathologies identified in the SA node were fat infiltration (43.48\%; fig.2), fibrosis (4.35\%), myxoid change (2.17\%; fig. 3 ) and hemorrhage $(2.17 \%)$. Fibrofatty infiltration of the SA node was the most common finding; it was seen in around $45.65 \%$ of cases. It was more common with an increase in age. Age wise distribution of various sinoatrial nodal lesions is tabulated in Table 3.

Fibromuscular dysplasia of the AV nodal artery was seen in $39.13 \%$ of sudden death cases (fig.4). The other microscopic features noted were fat infiltration(54.35\%; fig. 5), fibrosis (47.83\%), calcification (10.87\%; fig.6), chronic inflammation (32.61\%; fig.7), and hemorrhage (2.17\%). As with SA node, fibrofatty infiltration of the AV node was a common finding; it was seen affecting $71.73 \%$ of cases (Table 4). Age wise distribution of these lesions is tabulate in Table 5.

\section{DISCUSSION}

A detailed study of the conduction system was done to look for the various pathologies affecting the nodes in sudden death cases and to ascertain whether they contributed to the death of the individuals in anyway.

Charlton et $\mathrm{al}^{3}$ examined conduction system in 23 cases of sudden death. In his study, 19 cases showed abnormalities in the conduction system; FMD was seen affecting the nodal arteries in the age range of 26-76 years. In the present study, FMD was seen affecting the nodal arteries in the age range of $21-75$ years.

FMD of the nodal arteries was seen affecting young and old individuals alike; in both the study by Charlton et $\mathrm{al}^{3}$ and in 
Table:5 Age groups and microscopic features of AV node

\begin{tabular}{|c|c|c|c|c|c|c|c|c|c|c|c|c|c|c|}
\hline \multirow{3}{*}{$\begin{array}{c}\text { Microscopic } \\
\text { features in AV } \\
\text { node }\end{array}$} & \multicolumn{14}{|c|}{ Age Groups } \\
\hline & \multicolumn{2}{|c|}{$<25$} & \multicolumn{2}{|c|}{$25-34$} & \multicolumn{2}{|c|}{$35-44$} & \multicolumn{2}{|c|}{$45-54$} & \multicolumn{2}{|c|}{$55-64$} & \multicolumn{2}{|c|}{$\geq 65$} & \multicolumn{2}{|c|}{ Total } \\
\hline & No & $\%$ & no & $\%$ & no & $\%$ & no & $\%$ & no & $\%$ & no & $\%$ & no & $\%$ \\
\hline FMD & 1 & 2.17 & 1 & 2.17 & 2 & 4.35 & 0 & 0 & 0 & 0 & 0 & 0 & 4 & 8.7 \\
\hline Fat & 0 & 0 & 0 & 0 & 2 & 4.35 & 4 & 8.7 & 0 & 0 & 0 & 0 & 6 & 13.04 \\
\hline Fib & 0 & 0 & 1 & 2.17 & 1 & 2.17 & 1 & 2.17 & 2 & 4.35 & 2 & 4.35 & 7 & 13.04 \\
\hline FMD+Fat & 0 & 0 & 0 & 0 & 0 & 0 & 0 & 0 & 0 & 0 & 2 & 4.35 & 2 & 4.35 \\
\hline $\mathrm{Fat}+\mathrm{Fib}$ & 0 & 0 & 0 & 0 & 1 & 2.17 & 0 & 0 & 0 & 0 & 0 & 0 & 1 & 2.1 \\
\hline FMD+Fib & 0 & 0 & 0 & 0 & 1 & 2.17 & 1 & 2.17 & 0 & 0 & 1 & 2.17 & 3 & 6.52 \\
\hline FMD + Fat + Fib & 0 & 0 & 0 & 0 & 0 & 0 & 2 & 4.35 & 1 & 2.17 & 0 & 0 & 3 & 6.52 \\
\hline C.I & 0 & 0 & 0 & 0 & 2 & 4.35 & 0 & 0 & 0 & 0 & 0 & 0 & 2 & 4.35 \\
\hline Fat + C.I & 0 & 0 & 0 & 0 & 1 & 2.17 & 0 & 0 & 1 & 2.17 & 0 & 0 & 2 & 4.35 \\
\hline $\mathrm{Fat}+\mathrm{Fib}+\mathrm{C} . \mathrm{I}$ & 0 & 0 & 0 & 0 & 0 & 0 & 0 & 0 & 1 & 2.17 & 1 & 2.17 & 2 & 4.35 \\
\hline $\mathrm{FMD}+\mathrm{Fat}+\mathrm{Cal}$ & 0 & 0 & 0 & 0 & 1 & 2.17 & 0 & 0 & 0 & 0 & 1 & 2.17 & 1 & 4.35 \\
\hline $\begin{array}{l}\mathrm{FMD}+\mathrm{Fat}+\mathrm{C} \\
\mathrm{I}+\mathrm{Cal}\end{array}$ & 0 & 0 & 0 & 0 & 0 & 0 & 0 & 0 & 0 & 0 & 1 & 2.17 & 1 & 2.17 \\
\hline $\mathrm{Fat}+\mathrm{Fib}+\mathrm{C} . \mathrm{I}+\mathrm{Cal}$ & 0 & 0 & 0 & 0 & 0 & 0 & 0 & 0 & 1 & 2.17 & 0 & 0 & 1 & 2.17 \\
\hline FMD+Fat+C.I & 0 & 0 & 0 & 0 & 0 & 0 & 0 & 0 & 0 & 0 & 3 & 6.52 & 3 & 6.52 \\
\hline $\mathrm{Fib}+\mathrm{C} . \mathrm{I}$ & 0 & 0 & 0 & 0 & 0 & 0 & 0 & 0 & 1 & 2.17 & 0 & 0 & 1 & 2.17 \\
\hline $\begin{array}{l}\text { FMD+Fat+ } \\
\text { C.I+haem }\end{array}$ & 0 & 0 & 0 & 0 & 0 & 0 & 0 & 0 & 1 & 2.17 & 0 & 0 & 1 & 2.17 \\
\hline $\begin{array}{l}\mathrm{FMD}+\mathrm{Fat}+\mathrm{C} . \\
\mathrm{I}+\mathrm{Cal}\end{array}$ & 0 & 0 & 0 & 0 & 0 & 0 & 1 & 2.17 & 0 & 0 & 0 & 0 & 1 & 2.17 \\
\hline Unremarkable & 0 & 0 & 0 & 0 & 0 & 0 & 0 & 0 & 1 & 2.17 & 0 & 0 & 1 & 2.17 \\
\hline Not sampled & 0 & 0 & 0 & 0 & 1 & 2.17 & 0 & 0 & 0 & 0 & 0 & 0 & 1 & 6.52 \\
\hline \multirow[t]{2}{*}{ Total } & 0 & 0 & 1 & 2.17 & 2 & 4.35 & 0 & 0 & 0 & 0 & 0 & 0 & 3 & 6.52 \\
\hline & 1 & 2.17 & 4 & 8.7 & 13 & 28.3 & 9 & 19.57 & 8 & 17.39 & 11 & 23.9 & 46 & 100 \\
\hline
\end{tabular}

the present study. However, other degenerative changes like fibrosis and fat infiltration were seen more in the elderly in the present study, and was similar to the findings of Charlton et $\mathrm{al}^{3}$ and Suarez-Mier et al. ${ }^{2}$

A conduction system study was done by Lie et al. ${ }^{6}$ which included 49 sudden death cases. Lie et al6 found that intimal thickening with significant luminal narrowing occurred commonly in the nutrient vessels of the conduction system, affecting the SA nodal artery in $25 \%$ cases and the AV nodal artery in $50 \%$ of cases. In the present study, it was seen in $36.95 \%$ of SA nodal arteries and $39.13 \%$ of AV nodal arteries (Table 6). The incidence of FMD affecting the SA node artery was higher in the present study. The incidence of involvement of the AV node artery was less compared to Lie et al's study (Table 6).

A detailed study of sudden death cases in people $\leq 40$ years were studied during a 10 year period in Michigan and a 4 year period in Spain by Cohleet al. ${ }^{7}$ From both these centers 381 cases of SCDs were identified. In their study also, the most common cause of SCD were atherosclerotic
Table 6: Comparison of fibromuscular dysplasia in the nodal arteries

\begin{tabular}{ccl}
\hline Fibromuscular dysplasia & Lie et al $^{6}$ & Present study \\
SA node artery & $25 \%$ & $36.96 \%$ \\
AV node artery & $50 \%$ & $39.13 \%$
\end{tabular}

coronary artery disease, cardiomyopathy and myocarditis in that order. In 82 cases, no cause of death was identified. But, in $11 / 381$ cases $(2.9 \%)$, the cardiac conduction system contained lethal lesions like FMD of AV nodal artery(7 cases) and atrioventricular nodal tumors (4 cases).Hence they concluded that examination of the cardiac conduction system can yield very valuable information and hence should be made mandatory. ${ }^{7}$

Two cases of sudden death were seen in young individuals described by Michaud et $\mathrm{al}^{8}$ and 1 case was described by Zack et al. ${ }^{9}$

Michaud et al. ${ }^{8}$ described FMD of the nodal artery as a lesion often entirely seen within the tunica media, including 
Table 7: Comparison in the pathology of the conduction system in various studies

\begin{tabular}{|c|c|c|c|c|}
\hline $\begin{array}{l}\text { Pathology in conduction system (most } \\
\text { common changes) }\end{array}$ & $\begin{array}{c}\text { Charlton et al3 ( } 23 \\
\text { cases) }\end{array}$ & $\begin{array}{c}\text { Suarez - Mier et all ( } 33 \\
\text { cases) }\end{array}$ & $\begin{array}{l}\text { Lie et al6 } \\
\text { (49 cases) }\end{array}$ & $\begin{array}{l}\text { Present study } \\
\text { ( } 46 \text { cases) }\end{array}$ \\
\hline Medial hyperplasia of nodal arteries & $7(30.43 \%)$ & $3(9.09 \%)$ & $\begin{array}{l}\text { 13/49(26.53\%)SAnode } \\
\text { 24/49(48.97\%)AVnode }\end{array}$ & $\begin{array}{l}\text { 17/46(36.95\%)SAnode } \\
\text { 18/46(39.1\%)AVnode }\end{array}$ \\
\hline Fibrofatty change & $6(26.1 \%)$ & $11(33.33 \%)$ & $\begin{array}{l}\text { 9/49(18.37\%)SAnode } \\
\text { 21/49(42.86\%)AVnode }\end{array}$ & $\begin{array}{l}\text { 21/46(45.65\%)SAnode } \\
33 / 46(71.73 \%) \text { Avnode }\end{array}$ \\
\hline Presence of mononuclear cells & $7(30.43 \%)$ & - & - & 15/46(32.6\%)Avnode \\
\hline Presence of myxoid ground substance & $2(8.7 \%)$ & - & - & 1/46(SA node) $2.17 \%$ \\
\hline Haemorrhage in SA/AV node & $1(4.35 \%)$ & - & $2(4.08 \%)$ & $\begin{array}{l}2(1 \text { case in SAnode-and } \\
1 \text { in AVnode- } 2.17 \%)\end{array}$ \\
\hline Calcification & - & - & - & 5/46(10.87\%)Avnode \\
\hline AV nodal tumour & $1(4.35 \%)$ & $1(3.03 \%)$ & - & - \\
\hline
\end{tabular}

both fibrous and muscular components and the histologic organization is so disorderly that it is considered a dysplastic process. An obstruction of the arteries supplying the conduction system may cause electrical instability of the heart with arrhythmia and sudden death. In his study, he discussed sudden death in 2 young individuals, a 12 year old and a 32 year old. Both cases showed FMD of the AV nodal artery with narrowing of the lumen. This study illustrated the importance of examination of the intramural coronary arteries and the nodal arteries, particularly in cases of sudden death of young people who die without any obvious cause. ${ }^{8}$

Zach et al. ${ }^{9}$ examined the conduction system in a 12 year old boy who collapsed suddenly and died. The only abnormality detected was the extreme narrowing of the AV nodal artery with proliferation of smooth muscle cells with fibrosis of the media and partly of the intima. Here, the cause of death was attributed to the FMD of the supplying AV nodal artery. This case once again highlights the importance of conduction system study. ${ }^{9}$

A study was conducted by Burke et al. ${ }^{10}$ where he compared the AV nodal artery in 27 sudden death patients to 17 control patients who had accidental deaths. A dysplastic AV nodal artery with mucopolysaccharide deposition was seen exclusively in sudden death patients. They concluded that dysplasia of AV node artery may contribute to death in a substantial portion of patients with unexplained sudden death.

Cardiac conduction system was studied by James et al. ${ }^{11}$, in a 7 year old boy and in a 64 year old man. Both were cases of sudden unexpected death. Although both cases had additional histological abnormalities in the conduction system, the more striking feature was the fibromuscular dysplasia of the sinus node artery leading to narrowing of the lumen and reduction of blood flow. They concluded that FMD of the sinus node artery would have lead to some lethal electrical instability of the heart, as it is the pacemaker and hence sudden death.
Pathogenesis of FMD is still unclear. Congenital or acquired defects of smooth muscle/ collagen /elastin or congenital or acquired defects of local arterial innervations may all play contributory roles. Sinus node artery is an unusually stressed artery, coursing through a comparatively dense collagen sheath, which might render it susceptible to mural disease. $^{11}$

In the present study, 6 cases were seen with only conduction system abnormalities; no complicated coronary atherosclerosis or lesions were found in them.

Two were young boys of 21 and 25 years; the other was a 35 year old man. The only pathology detected in these hearts was FMD of the AV nodal artery. Three other cases were also seen, one a 35 year old female with FMD of the AV node artery; a 55 year old male with FMD affecting both SA and AV node arteries along with chronic inflammation and fibrosis of the nodes and a 41 year old man with FMD of the SA nodal artery along with fat infiltration in the SA node. No other significant pathology was detected in their hearts. So in all these cases we can safely assume that FMD of the nodal artery would have lead to electrical instability and sudden death, as stated in the literature ${ }^{8-11}$.

Hence; without any hesitation we can conclude that cardiac autopsy should be made mandatory in all sudden death cases; and in those where no pathology is detected, a complete study of the cardiac conduction system should be made a must.

In the present study, there were 4 cases of acute MI. All the 4 cases showed FMD of the nodal artery; in 2 cases it was seen involving both the SA and AV nodal artery, in the remaining 2 it was seen involving only the AV nodal artery. This finding is interesting as it may suggest that even though these patients had severe coronary artery disease, FMD of the nodal arteries could also have lead to electrical instability and caused sudden death in them. Hence, in the pathogenesis of sudden death, conduction system lesions must always be considered even in cases with severe 

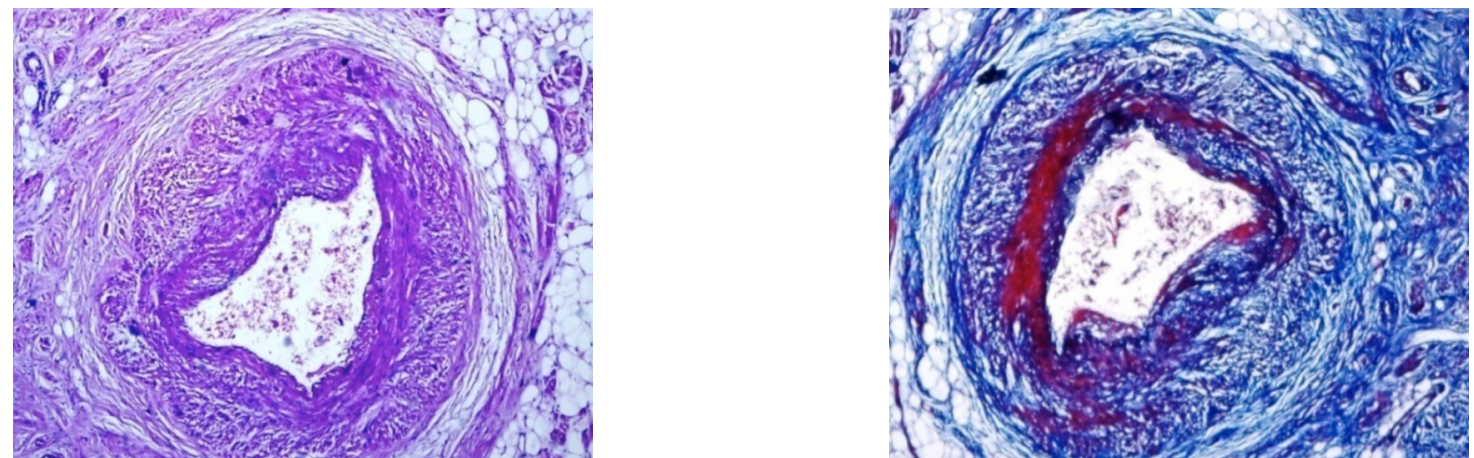

Figure 1A \& 1B: Fibromuscular dysplasia of SA node artery (A-HE Stain, X40\&B-MT Stain, X 40).

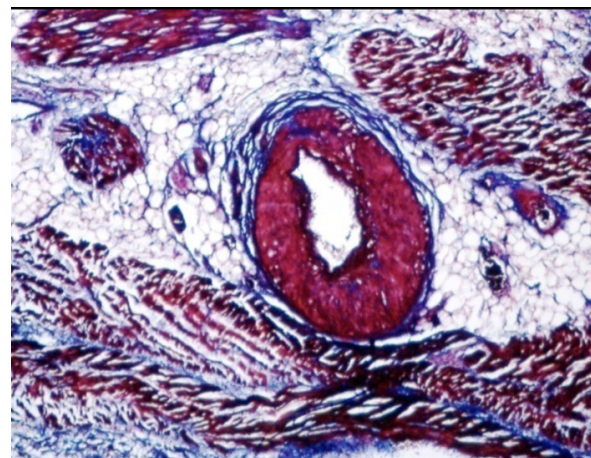

Figure 2: Fibromuscular dysplasia of SA nodal artery with fat infiltration (MT Stain, $X 40)$.

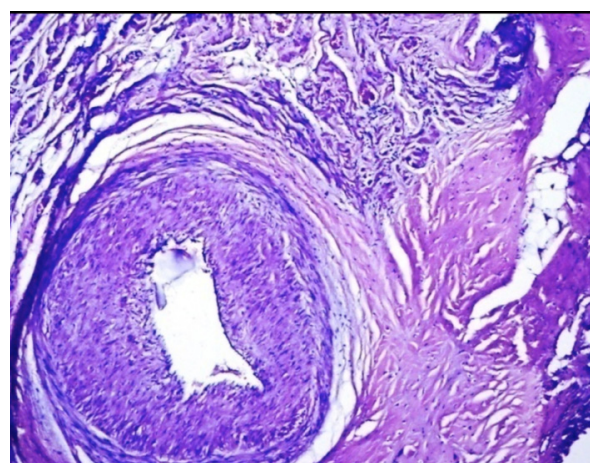

Figure 4: Fibromuscular dysplasia of $A V$ node $\operatorname{artery}(H E$ Stain, X40).

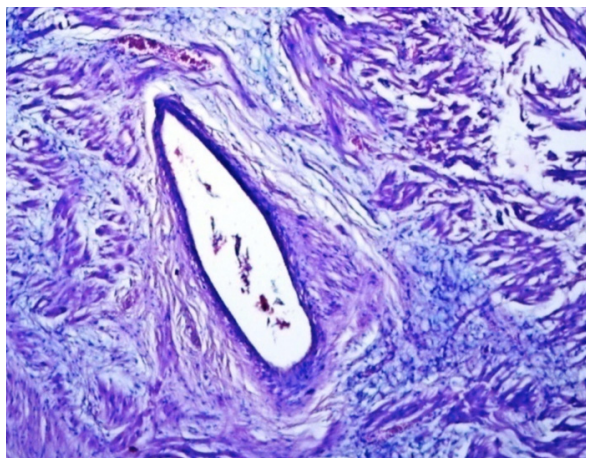

Figure 3: Myxoid ground substance in the SA node (HE Stain, X40).

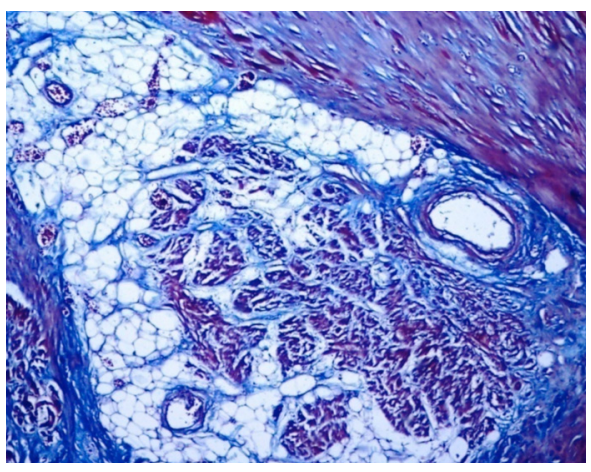

Figure 5: Extensive fat infiltration in the $\mathrm{AV}$ node (MT Stain, X40). coronary artery disease. ${ }^{1}$

FMD is histologically similar to arterial dysplastic changes seen in renal arteries and in other muscular arteries. Many individual reports have linked SCD with non-atherosclerotic narrowing of the SA and AV nodal arteries leading to fatal arrhythmias due to nodal ischemia. Sudden death could be due to lumen reduction in theses nodal arteries. ${ }^{12}$

Non-specific degenerative changes like fibrofatty infiltration of the nodes were just as prevalent in SCD. Fibrosis and fibrofatty replacement of the conduction tissue was more common with an increase in the age of patients ${ }^{1,3,6}$ both of these features were similar to our study. But compared to other studies, the incidence of fibrofatty infiltration of the nodes were higher in our study (Table 7), it was seen involving the SA node and AV node in $45.65 \%$ and $71.73 \%$ cases respectively which was much higher than the other 3 studies. (Table 7).

Presence of mononuclear inflammatory cells was seen in $32.6 \%$ cases which were slightly higher than the findings 


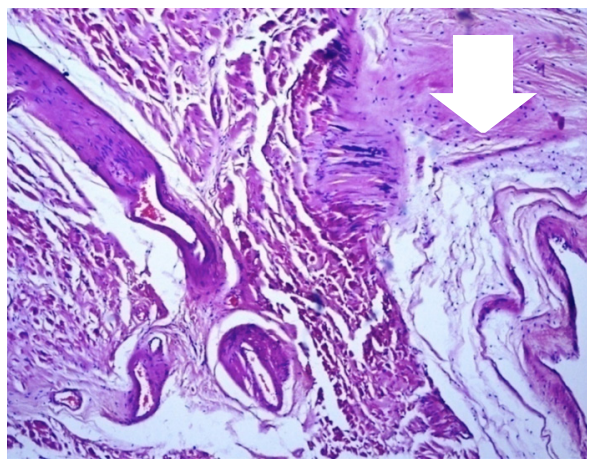

Figure 6: Calcification in AV node (arrow) (HE Stain, X40).

of Charlton et $\mathrm{al}^{3}$ (Table 7).Charlton et $\mathrm{al}^{3}$ could not explain these collections of mononuclear cells and they thought it was associated with remodeling of cardiac skeleton or with fat infiltration in the nodes. They postulated that these collections of mononuclear cells were a normal concomitant of these processes rather than a significant pathological abnormality. ${ }^{3}$ In our study we had one case with only chronic inflammation in the AV node as the only pathology detected in the heart.

The present study showed only 2 cases with haemorrhage in the nodes. Both cases were of acute MI. This was similar to the finding by Lie et $\mathrm{al}^{6}$ where they had 2 cases of haemorrhage into the nodes in cases of acute septal MI. They concluded that conduction tissue appeared more resistant to ischemic injury and was overtly damaged only in rare occasions of fatal acute MI (Table7). ${ }^{6}$

Calcification in the nodes is described by Gulino et al. ${ }^{12}$ They said that heavy calcification of the aortic valve or the mitral valve annulus may compress the conduction tissue or extend as calcific deposits into central fibrous body and conduction tissue. In these patients, SCD may occur as a result of heart block. Calcification was seen in $11.63 \%$ of cases in the present study (Table 7). It was seen in adults over the age of 40 years.

Myxoid ground substance around the nodes was seen in $19.36 \%$ of cases in the study by Charlton et al. ${ }^{3}$ In the present study, it was seen only in 1 case of sudden death in a 75 year old man (2.17\%).In our case it was seen around the SA node. According to literature the significance of this is not clearly understood. ${ }^{3}$

\section{CONCLUSION}

As the complete diagnosis of cardiovascular disease has been made possible with advances in diagnostic medicine like echocardiography and angiography; autopsy of the heart has been neglected and taken a backseat.

The majority of sudden deaths are caused by coronary artery

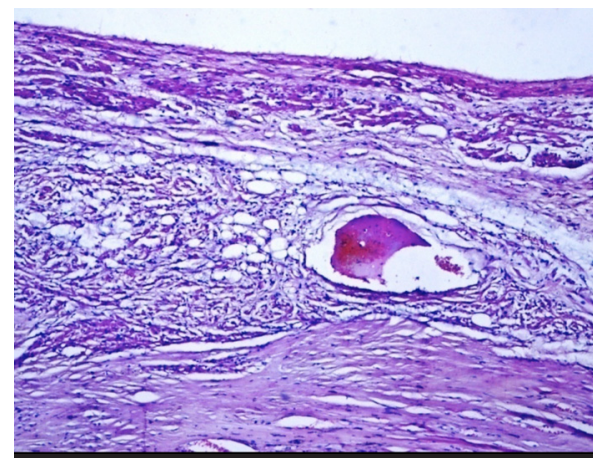

Figure 7: Chronic inflammation in the AV node with fat infiltration (HE Stain, X40).

disease; as seen in our study also. However, in few cases of sudden unexpected deaths, especially in the young; who die without any obvious cause, the study of the conduction system should be made mandatory because it may help to throw some light on the cause of death.

In the present study, there were $13.04 \%$ sudden death cases which had conduction system abnormalities as the only pathology detected; which could have lead to their demise. The conduction system lesions most likely causing sudden death was found to be of vascular origin (fibromuscular dysplasia of the nodal arteries); which can lead to lethal electrical instability and cardiac arrthymias.

Hence, we conclude saying that the examination of the cardiac conduction system is a useful adjunct in the examination of the heart in cases of sudden death, especially in the young.

"The motion of the heart is best understood by God alone". ${ }^{13}$

\section{REFERENCES}

1. Suarez-Mier MP, Fernandez-Simon L, Gawallo C. Pathologic Changes of the Cardiac Conduction Tissue in Sudden Cardiac Death. Am J Forensic Med Pathol 1995;16:193-202. Crossref

2. Gupta R, Joshi P, Mohan V, Reddy KS, YousufS.Epidemology and causation of coronary heart disease and stroke in India. Heart 2008;94:16-26. Crossref

3. Charlton I, Williams R. Cardiac Conducting Tissue - A Simplified Technique for Examination of the SA and AV Nodes. Am J Forensic Med Pathol 1990;11:213-8. Crossref

4. Kasthuri AS, Handa A, Niyogi M, Choudhury JC. Sudden death: a clinicopathological study. J Assoc Physicians India 2002;50:551-3. Crossref

5. Virmani R, Roberts WC. Sudden Cardiac Death. Human Pathology 1987; 18:485-91. Crossref

6. Lie JT. Histopathology of the Conduction System in Sudden Death from Coronary Heart Disease. Circulation 1975;51:446-52. Crossref

7. StephanCD,Suarez-MierMP,BeatrizA.Sudden death resulting from lesions of the cardiac conduction system.Am J Forensic Med Pathol 2002;23:83-9. Crossref

8. Michaud K, Romain N, Brandt-Casadevall C, Mangin P. Sudden Death Related to Small Coronary Artery Disease. Am J Forensic Med 
Pathol 2001;22:225-7. Crossref

9. Zack F, Terpe H, Hammer U, Wegener R. Fibromuscular dysplasia of coronary arteries as a rare cause of death. Int J Legal Med 1996;108:215-8. Crossref

10. Burke AP, Subramanian R, Smialek J, Viramani R. Nonatherosclerotic narrowing of the atrioventricular node artery and sudden death. J Am CollCardiol 1993;21:117-22. Crossref

11. James TN, Marshall TK. Multifocal Stenoses Due to Fibromuscular Dysplasia of the Sinus Node Artery. Circulation 1976;53:736-42. Crossref

12. Gulino SP. Examination of the Cardiac Conduction System-Forensic Application in Cases of Sudden Cardiac Death. Am J Forensic Med Pathol 2003;24:227-38. Crossref
13. Harris DF. The man who discovered the circulation of blood. The Popular Science Monthly 1913;29:453-67. 